\title{
Donación de Sancho I de Mallorca de un antiguo cementerio judío a la ciudad de Mallorca
}

\author{
Antonio Ortega VilLoslada
}

\begin{abstract}
RESUMEN ABSTRACT

En 1319 Sancho I de Mallorca dona a la ciudad y a los Jurados de Mallorca unos terrenos, antiguo cementerio judío, para la construcción de una nueva atarazana. Esta donación se enmarca en la política de la monarquía mallorquina destinada a favorecer a sus súbditos para poder hacer frente a la presión ejercida por

Pedro el Ceremonioso para reincorporar el Reino de Mallorca a la

In 1319 Sancho I of Majorca done to the city and to Sworns of Majorca some terrains, ancient cemetery jew, for the construction of a new shipyard. This donation was framed in the politics of the monarchy of Majorca destined to favor to the subjects to be able to stand up against the pressure exercised by Peter the Ceremonious for to join the Reign of Majorca to Crown of Aragon.
\end{abstract} Corona de Aragón.

\section{INTRODUCCIÓN}

La figura de Sancho I de Mallorca ha sido vista tradicionalmente por la historiografía como un rey de condición mansísima o con una gran falta de carácter ${ }^{1}$, aunque estudios más recientes lo sitúan como un rey especialmente sensato ${ }^{2}$ y prudente administrador. En este aspecto, Sancho I recogía el fruto de la política iniciada por Jaime I y desarrollada por Jaime II en su se-

- Era de condición mansisima, misericordioso y bueno para los vasallos; y su salud delicada y la afección asmática que le afligía, forzándole a la soledad de los montes en busca de aires puros, favorecian aquella disposición de ánimo. PifERrer: Islas Baleares, p. 51. También Martinez FerRando tiene una opinión semejante: Manca de carácter, feblesa, temperament limfatic, docil y de bona pasta (falta de carácter, debilidad, temperamento linfático, dócil y bueno).

2 Santamaría, A. Tensión Corona de Aragón - Corona de Mallorca. la sucesión de Sancho de Mallorca (1318-1326), p. 424. 
gunda etapa de reinado, dirigida a la creación de un reino económicamente solvente, capaz de desarrollarse por sí mismo. Desde inicios del siglo XIV el Reino de Mallorca habían alçanzado un considerable desarrollo, tanto económica como brganizativo. Sancho limpulsó al comercio y no dudó en intorvenir como un mercader más en el trático orientado hacia Flandes e Inglaterra. Incluso acaricio un plan de construcciones navate pera poder competir ventajosamente, con una thata propia de gateras, con el comereio genovés y veneciano, aunque parece que no llegó a reatizarse. Por otra parte, y dentro del desarrollo de Mallorca, también se preocupó por mantener una política urbanística encaminada al desarrollo del comercio y la navegación.

\section{SANCHO IY LOS JUDIOS DE MALLOORCA}

Las relaciones establecidas entre la Monarquía mallorquina y el pueblo hebreo no difieren sustancialmente de las mantenidas por otras casas reales peninsulares.

Desde la conquista de la iśla, Jaime I se mostrará muy interesado en mantener e incluso aumentar la presencia judía en la isla como buenos intermediarios comerciales con el mundo musulmán, y por su capacidad para el comercio. Pocos años después de la conquista, Jaime I inutilizaba una alhóndiga de los cristianos y se la entregaba a los judíos como terreno para cementerio. En 1247 concedia el rey una carta de salvoconducto y nacionalidad a todos los judíos que por tierra o por mar quisieran establecerse en sus tierras de Baleares, Cataluña o Valencia, y en la temprana fecha de 1254 descentralizaba los tributos de los judíos mallorquines de los judíos catalanes y aragoneses ${ }^{3}$, lo que significaba en la práctica la separación de las aljamas mallorquinas de las del resto de la Corona de Aragón. Aljama que tenia su ubicación en época musulmana en las inmediaciones del palacio de la Almudaina ${ }^{4}$, residencia real tanto para musulmanes como, posteriormente, para cristianos. Su ubicación pronto constituyó un problema urbanístico pues estaba situada en una zona privilegiada de la ciudad y la necesidad de un nuevo lugar para la reagrupación total de los judíos mallorquines ${ }^{5}$ pronto fue evi-

3 FiTA, Fidel, y Llabres, G.: Privilegios de los Hebreos mallorquines, B.R.A.H., tomo XXXVI, documentos 1 y 6. También Pons, A.: Judíos del Reino de Mallorca..., vol II, A.R.M. Códice Pueyo, fol. $\bar{x}$. El documento está fechado en Olite el 11 de diciembre de 1254.

4 Poco antes de la redacción del Códice Catalán del Repartimiento, laime l cedió a la comunidad judia un palado situado junto al portal y el muro de la Atmudaina: ... portale ot murum Almudaina maipris qui aspicit usque riariam. Riefa Frau, M.: Evolució urbana..., p. 87.

5 Según documentación de la época - ver nota número \&- la aljama que existía cuando Jaime 1 conquistó Mallorca no incluía la totalidad de la población judia y hay testimonios de judios viviendo por distintos lugares de la ciudad. 
dente. Jaime li de Mallorca confirmaba a los judíos mallorquines sus privilegios en 1280. En 1285 Alfonso el Liberal, dentro de una política dirigida a la aceptación de la nueva situación creada con la ocupación de Mallorca ${ }^{6}$, confirma los privilegios y franquezas de los mallorquines y expresa su deseo de que los judíos vivan juntos en un lugar de la ciudad. En 1298 el mallorquín Jaime II recupera sus posesiones en virtud de los acuerdos de Agnani de 1295 y en 1299 ya se encuentran judíos instalados en la zona del Temple y de la Calatrava ${ }^{7}$. En 1300 Jaime 11 aprueba la nueva disposición del barrio judío ${ }^{8}$, pero no será hasta $1303^{\circ}$ cuando el rey hará obligatorio el trasiado, moderando el comercio en sus antiguas tiendas pero obligándoles a comer y dormir en la juderia o call. La relación entre el pueblo hebreo y Jaime II de Mallorca vendrá marcada por acontecimientos externos que hicieron que el monarca actuara contra los judíos. El 22 de enero de 1309 Jaime ll quitaba a los judíos el privilegio de no contribuir a la ayuda vecinal, destinada a subvenir las necesidades de la ciudad o del Reino como son las obras públicas. Ese mismo año se produjo un tumulto al propagarse la noticia de que algunos judíos habían asesinado a un niño, a ejemplo de sus correligionarios de Gerona. Jaime II suptica al obispo que castigue al aacerdote promotor de los aftercado. ${ }^{10}$.

La llegada al poder de Sancho I supuso para la aljama unos inicios esperanzadores pues l pueblo judío mallorquín recuperará todos los privilegios perdidos anteriormente ", vuelven bajo la protección real y mantienen la exención a participar en las cargas vecinales. Sin embargo este aparente clima de concordla se ve roto en $1315^{12}$ cuando Sancho I con-

6 Santamaría, A.: La política municipal de Alfonso el Liberal en el Reino de Mallorca (1285-1291), p. 1281.

7 Los terrenos de esta aljama situada al lado del castillo de la Almudaina fueron cedidos a los dominicos. En 1268 el todavía infante Jaime - a través de Cipresto de Riclos-entablaba negociaciones, que no fructificaron, con los dominicos para comprarles una porción de terreno con el fin de ampliar la Almudaina. Lo que indica que al menos legalmente los terrenos ya no pertenecian al pueblo judío. Los dominicos iniciaron la construcción de la iglesia conventual a finales de 1296 por lo que necesariamente los judíos residentes en la zona debieron iniciar el traslado hacia la nueva judería.

- VILLANUEVA, Jaime: Viaje literario ..., p. 332. En esta disposición reconoce que los judios han vivido, al menos desde la conquista cristiana, desperdigados por la ciudad: ... attendentes quod judei civitatis Majoricarum, qui consueverunt morari ot suas domos et habitacions habere itus Almudainam ot in allis locis civitatis Majoricarum, tranothorunt at stra domicilia in certo loco dicte civitatis, scilli. cot, in quosdam vicas vocatos partite Jempli et Calatrave...

9 Pons, A.: Los judios del Reino de Mallorca,..., vol. Hi, p. 215, documento 17: Mandamus vobis च Jaime II de Mallora, desde Perpiñán, a su Lugarteniente en la isla Dalmau de Garriga-quatenus omnes judeos, qui moratur extra callum judayeum civitatis faciatis et compellatis, visis presentibus, ad transforendum et mutandum se, et ad faciendam suam habitationem infra dictum callem et non pormitatis nec sustineatis, quod aliqui judei stent extra dictum callem, maneat nec moretur.

10 Documento publicado por Antonio Pons en su obra: Los judios del Reino de Mallorca durante los siglos XIII Y XIV, p. 226, documento 34.

11 Sentencias con fecha: 22 de junio de 1311 y 7 de marzo de 1313.

12 Según recoge la sentencia del 19 de septiembre del año 1315. 
fisca todos los bienes, muebles e inmuebles, a los judíos de la ciudad y los aplica al fisco real. El motivo exacto de tan dura condena no se conoce hasta el momento, pero se puede tratar de una contundente respuesta a la ejecución de ciertos crímenes, por parte de miembros de la aljama, no resueltos ${ }^{13}$. Poco tiempo después el propio rey Sancho I les devolvía prácticamente la totalidad de sus bienes a cambio del pago en efectivo de una gran multa cifrada en 95.000 libras mallorquinas, con la promesa de no molestarlos más y de recibirlos de nuevo bajo su protección y amparo. El poder económico de la aljama mallorquina se revela importante pues al cabo de tres años Sancho l entregaba a los judíos la carta de pago en la que manifiesta haber recibido 65.000 libras mallorquinas del total de las 95.000 adeudadas ${ }^{14}$. El monarca devolvía a los judíos parte de lo que les habia quitado y, a petición de los secretarios de la aljama, confirmó a perpetuidad la inmovilidad del call. Al año siguiente, el 21 de julio Sancho I emitía una orden desde Perpiñán por la que se instaba a expulsar de la isla a los judios no mallorquines que se comportasen de forma maliciosa, indiscreta, mezquina o fueran vagabundos, pues eran considerados perniciosos para la paz y convivencia entre los propios judíos de la aljama ${ }^{15}$. La recaudación de un nuevo subsidio para el rey motivará las protestas de los miembros de la aljama mallorquina contra sus propios secretarios encargados de la recaudación y la resistencia de las aljamas de Menorca e Ibiza al considerar éstos que no tienen los mismos privilegios que sus hermanos de Mallorca. La respuesta del monarca será la imposición de penas a los que se resistan a pagar y la unificación de las tres aljamas en una sola, adquiriendo Menorca e lbiza los mismos derechos pero también las mismas obligaciones ${ }^{16}$.

13 Pons, A.: Los judíos del Reino de Mallorca..., vol. II, p. 238, documento n. 50 (1315, 19 septiembre, Mallorca): ...Attendentes quod ex certis criminibus condempnavimus universos et singulos judeos aljame civitatis Maojoricarum in amissione ornnium bonorum eorum, tam nobilium quam immobilium, prout in nostra sententia inde lata, latius continetur...

14 Con fecha: 28 de marzo de 1318. De la cantidad recibida, Sancho 1 destinó parte a condonar todas las deudas que tenian los cristianos con los judios. PONS, A.: Los judíos del Reino de Mallorca..., vol. II, p. 38.

15 A.R.M. Códice Pueyo, fol. 19v.: ...quod ad civitatem et regnum Majoricarum concurrunt passim judei et judee alienigeni vagabundi, qui propter malitiam aut negligentiam vel indigentiam, sua propia temeritate aut per alios inducti, ponunt discordias et inimititias inter judeos nostros dicte aljame, ex quibus judei ipsi gravamina, dampna et scandala frequenter incurrunt. Et cum velimus, prout decet, terras nostras talibus malis personis, seminantibus çiçaniam, expurgari, mandamus locum nostrum tenenti... ... ad requisitionem secretariorum aljame Majoricarum... ...de regno Majoricarum expellat, imponendo illis certam penam idoneam juxta conditionem earum quod nunquam regressum habeant ad dictum regnum...

16 A.R.M. Códice Pueyo, fols. 25 y 26. Ambos documentos están hechos en Perpiñán el 23 de agosto de 1319. La unificación en una única aljama dejaba a los judíos menorquines e ibicencos sin ningún argumento con el que oponerse a la talla pues pasaban a tener la obligación, de hecho, de contribuir en el impuesto decretado por el soberano. 
Los últimos años del reinado de Sancho I son de una buena armonía con los judíos. Por privilegio de 7 de julio de 1323, concedía a los judíos el traslado de la capilla de la Santa Fe que se habia constituido dentro de la aljama después de la confiscación de todos sus bienes ${ }^{17}$ y la apertura de una nueva puerta de acceso a la judería.

\section{DONACIÓN DEL ANTIGUO CEMENTERIO PARA SU USO COMO ATARAZANA}

El 6 de noviembre del año 1319 Sancho I donaba, desde Perpiñán, a los jurados y a la Universidad de Mallorca unos terrenos, que antiguamente habian sido cementerio judío ${ }^{18}$, para que se usara como atarazana 0 para lo que los jurados decidieran manteniendo en todo momento su carácter de lugar público ${ }^{19}$. Este tipo de donaciones no son infrecuentes, pues en 1263 Jaime I de Aragón cedia al monasterio de Valmagne, en Montpelier, un antiguo cementerio judío para construir un estudio de Teología 20.

Los terrenos habrían pasado al patrimonio regio como consecuencia del embargo sufrido por la aljama mallorquina con motivo de la sanción impuesta en 1315 y aunque se devolviese a los judíos gran parte de su patrimonio, algunas propiedades no revertieron de nuevo a sus antiguos titulares, pasando de forma indirecta a titularidad cristiana ${ }^{21}$. El documento

17 A.R.M. Códice Pueyo, fols. 20 y 21: ... hiis annis, tempore videlicet generalis condempnationis judeorum, confiscassemus nobis scholam et domum schole judeorum ipsorum quam habebant in civitate Majoricarum et postea in schola ipsa fecissemus ex causa capellam ad decus et nomen Sancte Fidei...

18 En sentido contrario, los judios de Mallorca se habian visto favorecidos por Jaime 1 que, después del reparto de la ciudad y de la isla, inutilizó una alhóndiga extramuros perteneciente desde antes de 1230 a comerciantes cristianos y la cedió al pueblo judío para que usasen el terreno como cementerio: ...illud alfondegum, extra civitatem, in quo christiani, tempore maurorum, consueverant comorari, sicut clausum est undique... CATEuRA Bennasser: Repoblación, urbanización..., p. 99 .

19 En este documento destaca la presencia del escribano real Lorenzo Plasensa, perteneciente a una familia de servidores reales, que ejerce su cargo con Jaime II y Sancho I. Sevillano Colom considera que ocupó el puesto de escribano real desde 1304 a 1315. Cuatro años después - 1319-, tal y como se ve en este documento, continúa en su cargo. Sevillano Colom, Francisco: De la Cancilleria de los Reyes de Mallorca (1276-1343), p. 223.

20 ... damus et concedimus, per nos et sucessores nostros, monasterio Vallismagne... ... in perpetuum, totum illum locum ab integro, quem habemus in Montepessulano, prope illum furnum nostrum, et iuxta hortum et domos Vallismagne antiquas in quo iudei Montispessulani sepeliri solebant, ad faciendum et construendum ibidem studium theologie... Publicado por HuICI MiRANDA, A., y CABANES PECOUAT, M.D.: Documentos de Jaime I de Aragón, vol. V, p. 34.

21 Como es el caso de la capilla de Santa $\mathrm{Fe}$, consagrada en la sinagoga existente en la judería antes de la confiscación de sus bienes. 


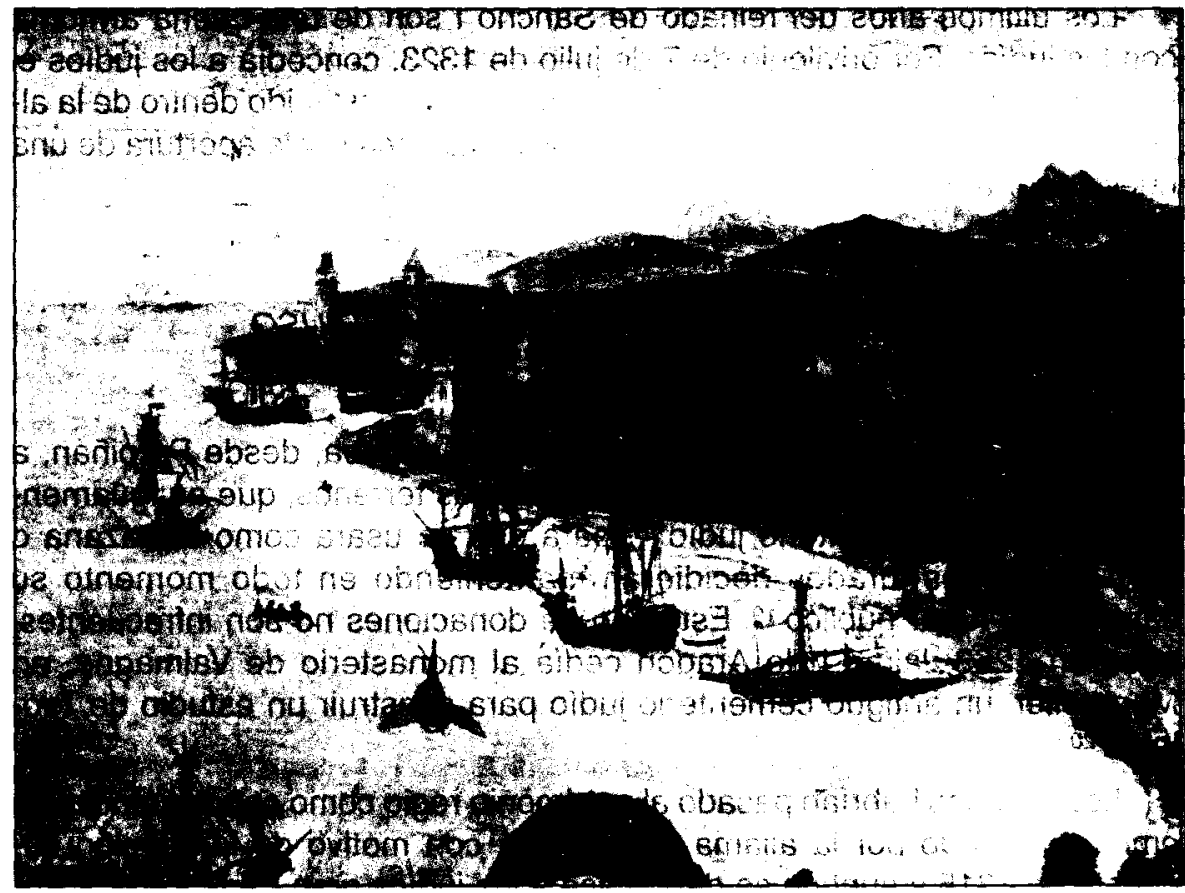

Las torres de Portop/ continuamente necesitaban reparaciones e incluso el faro esturo durente mucho tiempo fuera de servicio. En 1374 se repara la lámpara del faro después de muchos años sin funcionar. $Y$ pocos años después de pintarse esta obra, en 1515, se reconocia ta necesidad de repararlas pues estaban en estado ruinoso: ...adobar les torres de Portupi les quals stan en gran perill de ruynar...

expresa el deseo del rey Sancho de que los terrenos se usen como atarazana $u$ otros servicios públicos y de pública utilidad. Sin embargo, y aunque se muestra imperativo en este deseo, deja en manos de los jurados un uso alternativo de estos terrenos ${ }^{22}$, pues deja entrever la necesidad de adecuar el lugar para sus posibles usos.

Los inicios del siglo xIV son para Mallorca su época de máximo esplendor, tanto en lo referente a la demografía ${ }^{23}$ como a su fuerza como potencia comercial y maritima. La ciudad de Mallorca cuenta en esas fechas con dos

22 ...Et fiant ibidem cetera apta decensia et necessaria ac utilia, prout requirit condicio insius loci et culuslibet alterius ad usum et seruicium publicum deputati prout iurati Maioricanm deveret and nandum...

23 Según los datos del impuesto del morabetín de 1329, la población de la ciudad de Maman se situaría en unos 29.000 habitantes, de los cuales entre tres y cinco mil pertenecerian a la ajama de la ciudad. PIÑA Homs, R.: La creación del Derecho..., p. 63. 
atarazanas ${ }^{24}$. Una situada en el auténtico muelle natural de la ciudad, en la rada de Portopí, a varias millas de la ciudad. La otra en la parte baja de la ciudad, en la actual plaza llamada de Atarazanas, junto a la Lonja ${ }^{25}$.

Si la ciudad disponía de dos atarazanas ¿qué necesidad había de una tercera?. Son los mejores años del desarrollo comercial mallorquín y la necesidad de embarcaciones - la vida media de las embarcaciones no sobrepasa los 20 años 26 - obliga a la constante construcción para ir manteniendo la pujante flota mallorquina, por lo que no pueden extrañar los deseos de un monarca que también participaba, como un comerciante más, en los viajes comerciales a Flandes ${ }^{27}$, y que se muestra muy preocupado por llegar a tener una flota capaz de competir con la poderosa flota genovesa 28 .

\section{LOCALIZACIÓN DEL CEMENTERIO POR LOS TEXTOS}

En el documento se alude al cementerio judío que debió funcionar durante la época musulmana y los primeros decenios de la dominación cristiana, pues el cambio de ubicación de la aljama conlleva la creación de un nuevo cementerio que, según Antonio Pons ${ }^{29}$, estaría situado en las afueras de la ciudad, saliendo por la puerta llamada del Camp, al este

24 Entre 1354 y 1358 está documentado el uso como atarazanas más o menos improvisadas la plaza del muelie para construir una coca — in platea molli maris civitatis - o la ribera del barrio de la Calatrava, en el levante de la ciudad.

25 Sastre Moll, Jaime: El puerto de la Clutat de Mallorca..., p. 142.

26 Para Dufouro el promedio de existencia de una embarcación medieval no superaba los 10 años (L'Espagne Catalane et le Maghrib..., p. 42).

27 ...fideli nostro Franciscus Rossilionis, capitaneo galearum subditorum nostrorum que debunt in Flandria nauigare ut in flandria recipiat nomine nostro totum nolitum quod debebitur ex rebus e mercibus que vehentur in galea nostra noua... A.R.M. R.P. 25, fol. $25 \mathrm{v}$.

28 Sancho I se dirige desde Perpiñán a su lugarteniente en Mallorca Dalmau de Banyuis para que haga todo lo posible pare cambiar las cocas y naves par galeras: ... que lexades les coches e les naus, nauegas hom mercadeiam ab Galeras asi com ara fan totes les comunes per co que mal no puen prendre per lurs enamics... ...gran nostre e del Regne car a tota gent se poria hom fer tembre que hom poges dir que Mallorcha agues tantes galeres com vuy ha naus e Coches per que girats hi la cara aytant quant pugats que molt farets bona obre si adressament en podets donar e en apres nos qui subiranament naurem gran plazer. Datum a Perpenya, dimenge XXVIII jorns de juny del any de MCCCXX. ARM. Letras Reales $n .^{9} 6$, fols. 32v, 33. No tenemos noticias sobre la realización o no de este proyecto pero lo que se puede observar al estudiar los registros del ancoratge que han llegado hasta nuestros dias es que las naus como tal tipo de embarcación desaparecen del puerto mallorquín a partir de 1321 , último año en que aparecen registradas.

29 ...Item de una pessa de terra d'En Ramón Colell, situada prop l'hort que es diu d'En Salvador lo qual es tengut a cens de XXXII sous, pagadors a sent Miguel. E afronta de una part amb lo cami alt qui, partent del portal de Santa Fe, va vers lo fossar del jueus e d'altra part amb un carrerany qui va del dit cami vers la mar e d'altra part amb la riba de la mar... A.R.M. Capbreu de Manresa, fol. 758. Publicado por A. Pons en Historia de Mallorca..., p. 190. 


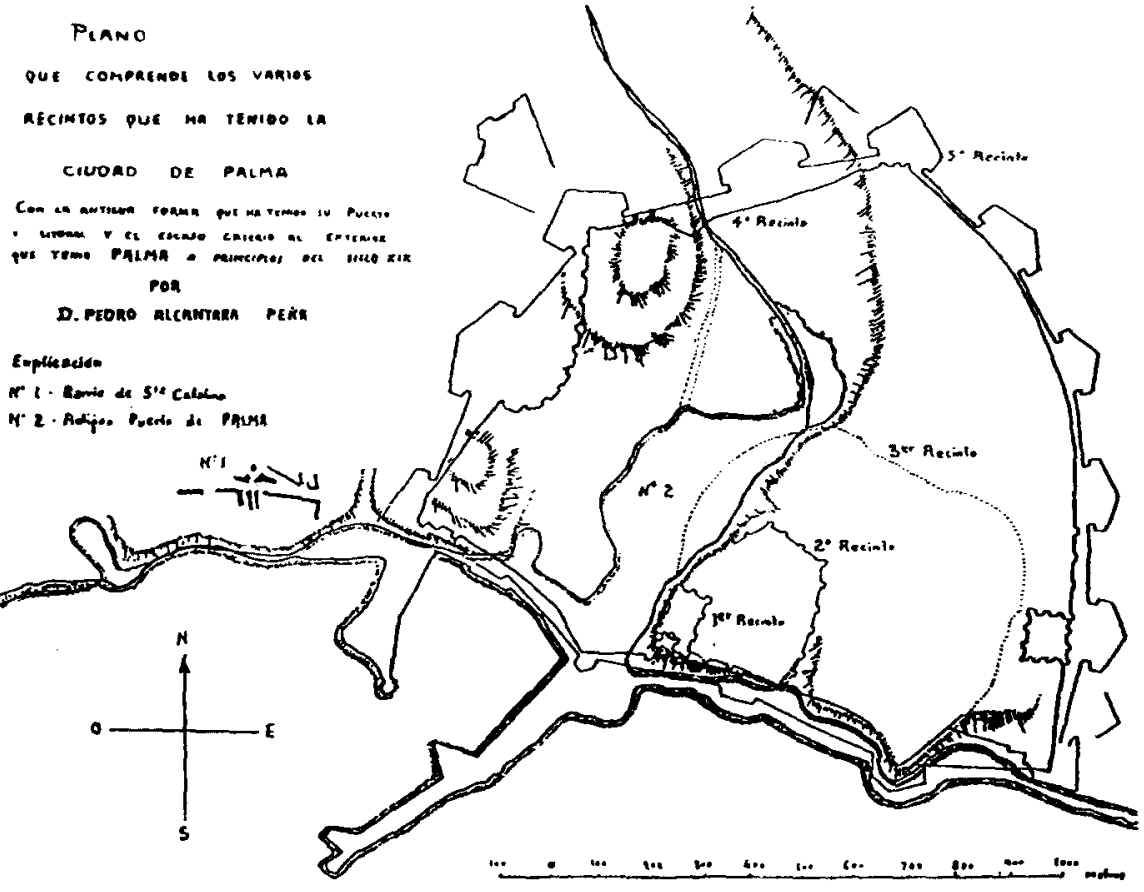

En la época de la dominación romana -corresponde al segundo recinto del plano- todavía existía una pequeña ensenada en la parte baja de la ciudad que servía de abrigo a las naves y actuaba como puerto de la ciudad romana. Esta ensenada -posterior cauce del torrentedividirá la ciudad en dos zonas bien delimitadas: la zona alta -a la derecha del plano-o vila d'amunt, densamente poblada, y la zona baja reservada inicialmente a pescadores y comerciantes, con una densidad de población muy baja.

de la ciudad. Cementerio que, al igual que el anterior, estará situado al lado del mar.

Indica el texto la situación de este antiguo cementerio judio: situado al exterior del dicho portal de la ciudad que se dice de Portopí. La ubicación parece sencilla pero la historiografia mallorquina no se pone de acuerdo en la localización exacta de la llamada puerta de Portopí. La referencia más antigua sobre esta puerta se encuentra en la descripción de la expedición pisano-catalana (1113-1115) sobre la ciudad de Mallorca ${ }^{30}$. La importancia de este poema reside en la fidelidad, para la literatura de la época, con que describe la fisonomía de la ciudad de Palma a principios del siglo XII, por lo que se le con-

30 Liber Maiolichinus de gestis pisanorum illustribus. Edición de CALISSE, A.: Instituto Storico ltaliano, Roma, 1904. Traducción al catalán a cargo de MuLEt MAS, Mireia. Palma de Mallorca, 1991. 
sidera punto de partida para los posteriores estudios sobre la organización urbana de la ciudad medieval hasta el siglo XVII ${ }^{31}$. En dicho poema se alude a esta puerta ${ }^{32}$ en la parte oeste de la ciudad, pues indica que está mirando hacia el puerto de Portopí, situado desde Palma a cuatro kilómetros en dirección oeste ${ }^{33}$. Esta indicación ha llevado a proponer diversas localizaciones en el muro occidental de la ciudad medieval aunque la ubicación exacta de la puerta nombrada en este documento sigue siendo muy problemática ${ }^{34}$.

Durante el asedio de las tropas de Jaime I, esta puerta aparece citada en tres ocasiones. En la primera se narra la salida del wâli almohade de Mallorca para parlamentar con las tropas cristianas ${ }^{35}$, en un intento de llegar a un acuerdo sobre la evacuación de los musulmanes mallorquines a cambio de riquezas. La segunda al indicar la estrecha vigilancia que hacen de las principales puertas ante el temor de la llegada de refuerzos desde el interior de la isla a la ciudad $^{36}$. La tercera mención se produce cuando las tropas cristianas entran en la ciudad y los habitantes huyen por puertas opuestas en dirección este y oeste ${ }^{37}$.

Una vez conquistada la ciudad, esta puerta no aparece mencionada como tal en el reparto de la ciudad entre las tropas cristianas ${ }^{38}$. Posteriormente las noticias referentes a esta puerta son muy escasas a pesar de

31 De esta fecha se conserva un plano, elaborado en 1644 por el presbitero Antonio Garau, en el que se observa la distribución medieval de la Ciutat de Paima. Existe en el Archivo de la Corona de Aragón un plano de 1596 levantado a propósito del proyecto de finalización de las nuevas murallas renacentistas, en el que se refleja el trazado de las murallas medievales junto al trazado de las renacentistas, sin aportar datos urbanos.

32 Aludiendo a una emboscada del conde de Barcelona sobre los moros que salen de la ciudad dice: Uibanam iuxta committens prelia portam,

Que portus spectat qui Pineus est vocitatus.

33 Ya en el siglo xill, la crónica de Jaime I nos indica, en boca del acaudalado mercader y experto marino Pere Martell, el uso que se hacía del puerto de Portopí durante los meses de otoño e invierno: ... e encara tot lo temps de primavera e de estiu tots los lenys e naus se fermen e estan davant la ciutat a una mila, mas al temps de autumne acostant-se al port, lo qual es luny de la ciutat dues miles e mitja, lo cual a nom Porto Pí...

34 Riera Frau, M." Magdalena: Evolució urbana..., p. 44. No se han encontrado restos arqueológicos que nos puedan indicar la localización de esta puerta, y autores como Alcántara Peña la colocan en la zona conocida como el Puig de Sant Pere, en línea con la actual calle de les Barques de Bou, mientras que esta autora la situa en la misma zona pero al final de la actual calle de Sant Pere, donde se han localizado restos de una torre, posiblemente musulmana.

35 Esobre açò envià'ns altra vegada missatge lo rei de Mallorques, que li enviàssem don Nuno e parlaria ab ell. E nós enviam-li: e isc el rei de Mallorques per la porta de Portopí... Llibre dels feits, cap. 76.

36 E metem mà a tres guaites fer, la una guaita si era als genys e a les cledes, l'altra si era contra la porta de Barbelec que és prop del castell que nós donam al Temple, la terça contra la porta de Portopi: e cascuna era de cent cavalls armats. Llibre dels feits, cap. 82.

3t E quan los sarraïns de la vila viren que la ciutat s'envaila, eixiren-se'n entre hómens $\theta$ fem. bres ben trenta mil.lia per dues portes, per la porta de Berbelet e la porta de Portopí e anaren-se'n a la muntanya. Llibre dels feits, cap. 86.

38 En el códice latino-arábigo del Repartiment de Mallorca se nombra como Bâb al-djadîd o Puerta Nueva. Riera Frau, M.: Evolució urbana..., p. 43. 
ser la principal vía de conexión entre la ciudad y su puerto. Vía que en los primeros años del siglo xIV se irá urbanizando y dotando de infraestructuras indispensables para la ciudad ${ }^{39}$. En esta misma línea se enmarca la donación de los terrenos del antiguo cementerio judío a los Jurados de la isla. Donación que se llevó a efecto pero que no tuvo resultados pues no consta que se adecuasen estos terrenos para edificar la atarazana. La situación económica del Reino de Maliorca se resintió en esas fechas debido a sus obligaciones como feudatario de la Corona de Aragón, ya que en 1321 Sancho I daba a Jaime II de Aragón un préstamo de 25.000 libras como ayuda a la conquista de Cerdeña. Las finanzas quedaron en una situación calamitosa y las peticiones de Jaime II de Aragón no contribuían a la recuperación financiera necesaria para poder afrontar obras de cierta envergadura ${ }^{40}$.

\section{LOCALIZACIÓN}

La localización exacta sobre el terreno de este antiguo cementerio es muy difícil, debido a los grandes cambios que ha experimentado la zona ya desde la época renacentista, cuando se procede a la construcción de las nuevas murallas, siendo esta zona oeste de la ciudad la más afectada.

La representación de la Ciutat de Mallorca más antigua que tenemos corresponde al cuadro de Pere Nissart ${ }^{41}$, en el que aparece representada la ciudad de Mallorca, su bahia y el puerto de Portopí.

39 En 1301 jaime II ordena la compra de dos solares frente a la puerta de Portopí con el objetivo de crear plazas frente a las murallas. La construcción del castillo de Bellver en el Puig de la Mesquita, a medio camino entre la ciudad y el puerto, será proyectado como residencia real y dehesa de caza y cumplirá con la misión de proteger el camino entre la ciudad y el puerto. La existencia de dos torres, de titularidad privada, en el camino de Portopí está documentada por la compra por parte del Real Patrimonio de dichas torres en 1332. En el mismo camino Jaime II autorizará en 1309 a Francesc Renovard la edificación de una capilla de su propiedad. Cateura Bennasser, P.: Las instalaciones portuarias..., p. 50 .

40 Después de la muerte de Sancho I se producen en la isla quiebras de bancos. En 1331 los Jurados de la isla tenian que responder a Jaime ll de Aragón que no le podían proporcionar más buques porque no habia más dinero pues ya le habían entregado un subsidio de 60.000 libras. CATEURA Bennasser, P.: Las instalaciones portuarias..., p. 50.

41 El retablo de San Jorge lo pinta Nissart entre 1468 y 1470 y si bien representa bastante fielmente la bahía de Palma y algunos de los edificios más característicos de la ciudad, se trata de una idealización de la ciudad tal y como lo indican algunos aspectos como la falta de la desembocadura del torrente de Sa Riera que en esa época cruza la ciudad - y que formaría una pequeña ensenada no recogida en el cuadro-, o la colocación de una puerta a nivel del mar en el lugar que ocupa el Puig de Sant Pere. Por lo que no se puede tomar como referencia para la localización de la puerta de Portopí. 


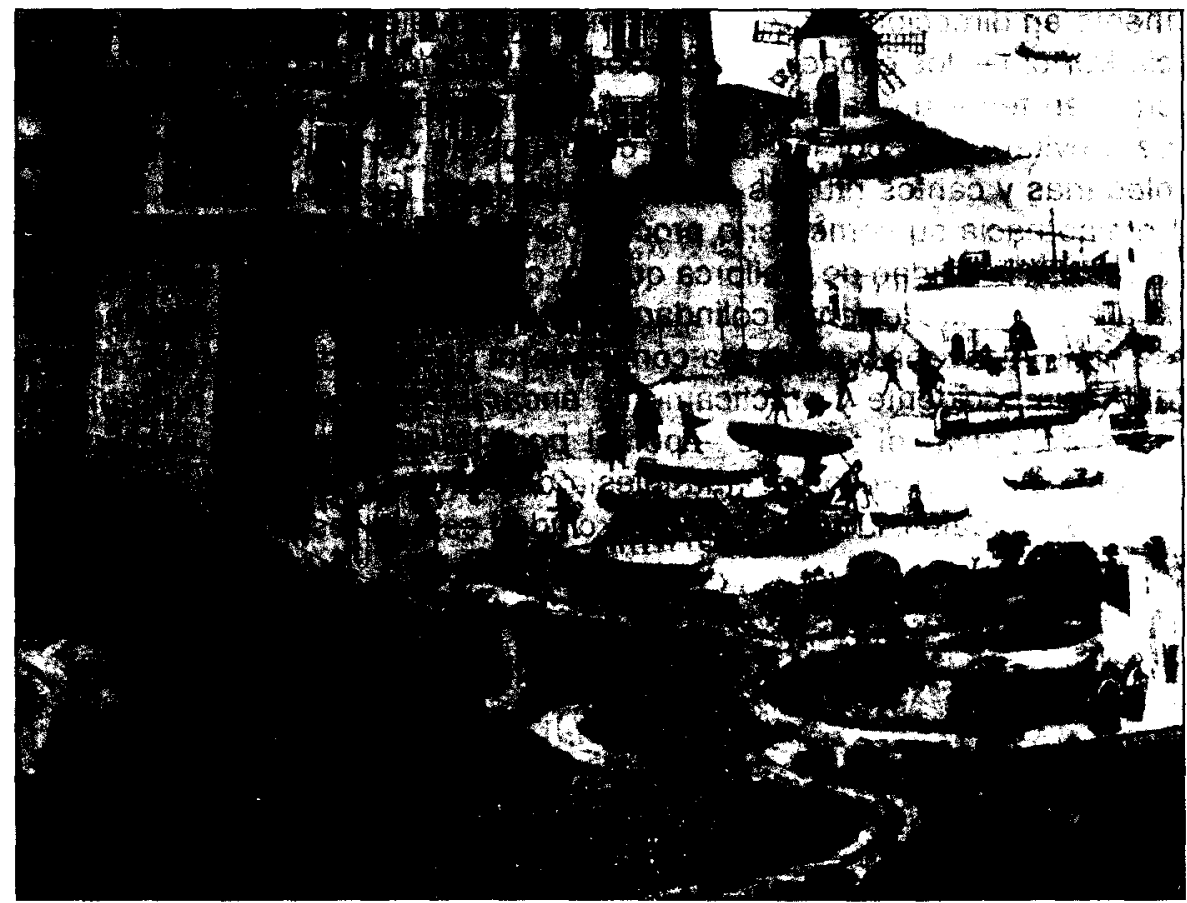

Fragmento del cuadro de Pere Nissart en el que se aprecia la ribera de Palma, el llamado muelle nuevo construido en el siglo XIV - probablemente en la segunda mitad-y el muelle de madera utilizado por las barcas encargadas de la carga y descarga de las naves.

Sancho I dona los terrenos para la construcción, según su deseo, de una nueva atarazana, por lo que los terrenos pertenecientes antiguamente al pueblo hebreo en donde se hallaba dicho cementerio debian llegar necesariamente hasta el mar. El pueblo judío procuraba cumplir unas mínimas normas a la hora de ubicar el emplazamiento de sus cementerios ${ }^{42}$. En primer lugar debían situarse fuera del recinto de la judería y de las propias murallas de la ciudad. Si era posible se elegía un lugar elevado en tierra no cultivada y se procuraba que el camino entre la judería y la "casa de eternidad" - bet olam- mediase un curso de agua ${ }^{43}$.

Cuando se produce la conquista cristiana la aljama está situada al lado del castillo de la Almudaina. La ciudad se había expandido principal-

42 La necesidad de tener un lugar en donde poder enterrar a sus muertos según sus propios ritos era para los judios una obligación fundamental que primaba sobre la construcción de la sinagoga.

43 Cantera Montenegro, E.: Aspectos de la vida cotidiana de los judíos..., p. 168. 
mente en dirección norte y este 44 mientras que en dirección oeste - hacia Portopi- los espacios habitados son muchos menos. Los judíos procuraban tener un camino lo más directo posible hacia sus cementerios para evitar pasar por los barrios cristianos en donde debían acallar sus plegarias y cantos rituales al pasar delante de las iglesias; por lo que el camino hacia su cementerio procuraban realizarlo por zonas poco habitadas. En la ciudad de Mallorca quedó, como recuerdo de la ubicación de la aljama en los terrenos colindantes con la Almudaina, una puerta situada en la Alcazaba y conocida como puerta de los judíos. Estaba orientada hacia occidente y prácticamente encaraba la puerta de Portopí después de cruzar el torrente - por el pont dels sastres-y subir por la actual calle San Felio hacia la iglesia de Santa Cruz. Según los conocimientos actuales, la zona baja de la ciudad estaría reservada al comercio

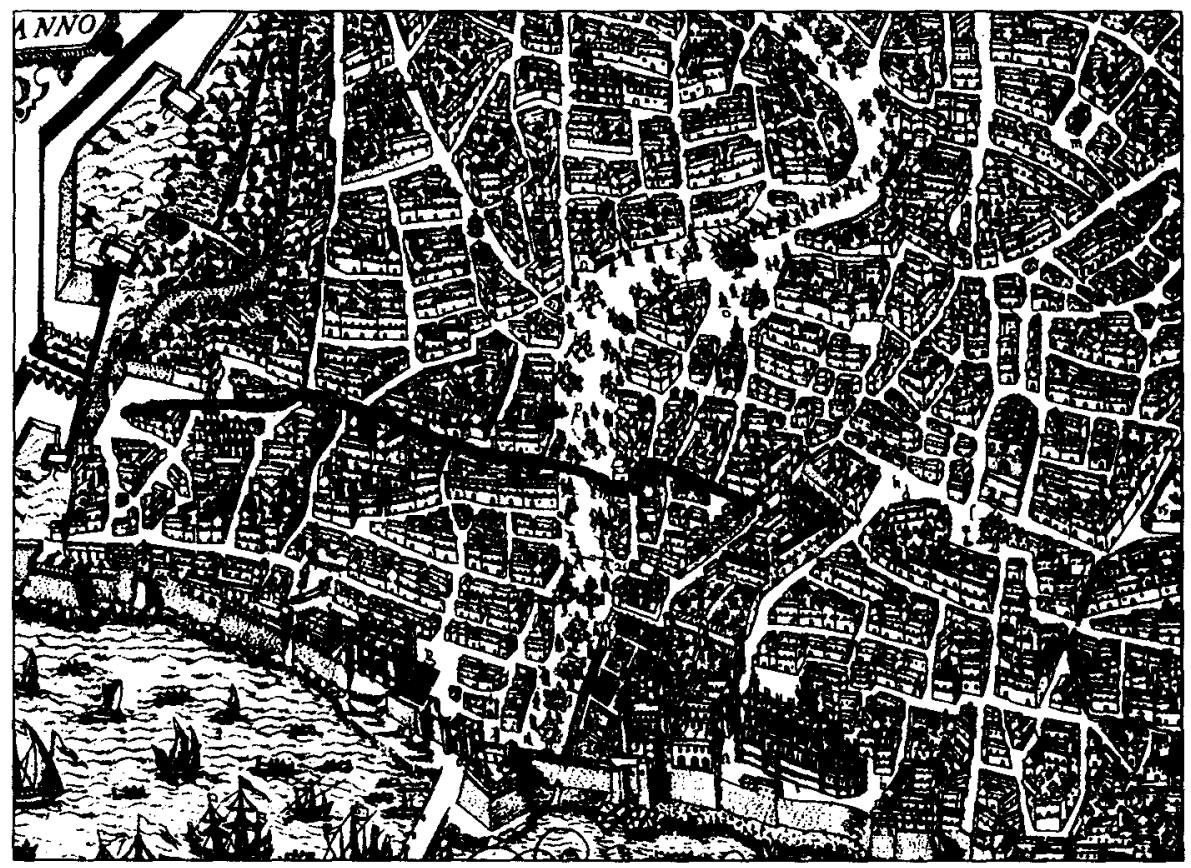

El itinerario marcado indica el camino más probable utilizado por los judíos de Palma, hacia la llamada puerta de Portopi, en sus procesiones fúnebres. Durante el dominio musulmán y la primera mitad del siglo xill esta zona de paso estaria muy escasamente poblada

44 En la zona que corresponde desde el lecho del torrente de la Riera hacia el este y que se conoce como vila d'amunt - ciudad alta- por encontrarse más elevada con respecto a la llamada vila d'avall situada a la altura del torrente y que se encuentra en esos momentos en fase de desarrollo. 
Donación de Sancho I de Mallorca de un antiguo cementerio judío a la...

y viviendas de gente dedicada al mar, siendo la zona costera la más poblada. Por lo que la ruta indicada anteriormente discurriría por una zona relativamente despoblada y en dirección contraria de la zona fuertemente habitada ${ }^{45}$.

Las referencias documentales para intentar situar exactamente esta puerta tampoco aportan datos definitivos. Los documentos apenas mencionan operaciones inmobiliarias en esta zona frente a la abundancia de datos referentes a las puertas de la parte alta de la ciudad que era el centro vital en donde se encontraba la gran mayoría de los servicios urbanos ${ }^{46}$. La documentación cristiana pasó a llamar esta puerta de Portopí como de Santa Catalina por encontrarse cerca de un hospital para marineros ${ }^{47}$ situado en el único arrabal de la ciudad, en el camino hacia el puerto de Portopí 48 . En el siglo xv la muralla de la zona oeste de la ciudad se encontraba en estado ruinoso, por lo que los jurados de la isla debieron afrontar los costes de la reparación de los lienzos de la muralla que estaban derruidos en la zona de la puerta de Portopí, en dirección al mar ${ }^{49}$.

Recientemente se ha descubierto una torre de origen musulmán en la zona conocida como baluarte de San Pedro, en el extremo occidental de la muralla ${ }^{50}$. Comunica directamente a través de la calle de San Pedro con la plaza de las atarazanas, la Lonja y el palacio real. Está situada en el ángu-

45 Con la conquista cristiana esta ruta se verá jalonada por edificios religiosos cristianos como la iglesia de Santa Cruz o el Oratorio de San Felio, promovido por el abad del monasterio de Sant Feliu de Gixols, lo que sin duda plantearía roces entre ambos colectivos.

4 Todos los mercados se encontraban en esta zona al este del cauce del torrente que servía para dividir la ciudad . La zona este - la parte alta o vila d'amunt-correspondía a la primera ciudad romana y las posteriores ampliaciones hasta el siglo XII en que según el Liber Maiolichinus la ciudad ya contaba con los recintos conocidos actualmente. Era la zona densamente habitada y que contaba con todos los servicios necesarios. De las catorce mezquitas conocidas, doce se encontraban en esta zona de la ciudad. Y las dos restantes de la zona baja de la ciudad se han localizado muy alejadas de la zona litoral. Riera FraU, M.: Evolució urbana..., páginas 108, 122.

47 Hospital fundado por el mercader Ramón Salelles bajo la advocación de Santa Catalina y que posteriormente pasará a manos de los Trinitarios.

48 Barcelo Crespl, M.: Retrat de la ciutat de Mallorca..., p. 112

49 En 1459 el Gran i General Consell hablaba de: adobar e reparar lo peu del portal de Santa Catalina o de Portupi. En 1460 los jurados contrataban al maestro Vilasclar porque: cum turries et murus sive lo peu portalis vulgariter nuncupati de Sancta Catharina indigeret máxima reparacione... En 1464 los jurados llegaban a un acuerdo con los obreros en relación a la piedra que debian cortar...per la obre la qual de present se deu comensar en la part del mur de la present ciutat lo qual és cahut per lo portal de Santa Catarina devers la mar. BARCElo Crespi, M.: Retrat de la ciutat de MaHorca..., p. 111.

50 En el plano del Archivo de la Corona de Aragón de 1596 los lugares en donde se encuentran las distintas puertas son remarcados con unos puntos de tinta más gruesa e indicando, en los más importantes, el nombre de dichas puertas. Sin embargo aparecen algunos puntos sin indicar el nombre y uno de ellos corresponde al lugar en donde se ha encontrado esta torre musulmana y en donde necesariamente debía haber una puerta. 
to que forma la muralla entre el mar y el talud ${ }^{51}$ que corre paralelo a la calle Pólvora. El desnivel existente entre esta torre y lo que sería el arranque del camino de Portopi hacen difícil que sea ésta la puerta buscada pues está situada en el punto más elevado, lo que obligaría a un esfuerzo superfluo en el transporte de las mercaderías.

En el plano de Garau de 1644 aparece en la muralla medieval cerca de la puerta que indica como de Santa Catalina y a su izquierda, en dirección al mar, una puerta tapiada que podría corresponder a la antigua puerta medieval. Si dentro de la ciudad el desnivel que hay que salvar entre el torrente de la Riera y la puerta de Santa Catalina o la recientemente propuesta como puerta de Portopi, al lado de la torre musulmana, es semejante, el tramo exterior a la muralla tiene una pendiente mucho más suave en la zona de la puerta conocida como de Santa Catalina, lo que facilitaría el transporte de materiales y mercancías. Por otra parte, los principales centros comerciales y de negocios de la ciudad se encontraban, como ya he indicado, al otro lado del cauce de la Riera lo que obligaba a transportar los productos procedentes del puerto de Portopí o de los pueblos del poniente insular a través de la ciudad. Para ello debían descender hasta el cauce del torrente y atravesarlo para llegar a la conocida actualmente como Plaça del Mercat - situada al nivel del cauce de la Riera- en donde estaría el mercado central 52 y superar el desnivel hacia la parte alta de la ciudad en dirección a las actuales calles de San Miguel o Sindicato.

\section{CONCLUSIONES}

1319 es un año de preocupaciones para Sancho I de Mallorca pues la falta de descendencia directa por parte del monarca dejaba a la dinastía mallorquina en una posición de debilidad diplomática ante los constantes deseos del monarca aragonés por reincorporar el Reino de Mallorca a la Corona de Aragón. El año anterior Jaime II de Aragón había comunicado en Tortosa a Sancho I su intención de restituir el Reino de Mallorca a la Casa de Aragón alegando la falta de descendencia en la corona mallorquina. A lo que Sancho replicaba con el testamento de Jaime I que le permitía designar heredero según derecho ${ }^{53}$ en la persona de Jaime,

51 Este talud corresponde a la zona que comprende la actual avenida Argentina.

52 De los mercados conocidos es el único en el que se ha documentado la existencia de un abrevadero para los animales

53 Santamaría, A.: Tensión Corona de Aragón - Corona de Mallorca..., p. 430. 
hijo de su hermano Ferran. La desavenencia entre ambos monarcas se tradujo en una presión política y pseudomilitar - a través del corso- sobre Mallorca.

Ante la disputa diplomática desarrollada por ambas cancillerías ${ }^{54}$, la concesión de unos terrenos para un uso tan vital para la economía mallorquina como era el comercio ${ }^{55}$ se convertía sin duda en un buen argumento político a favor de la monarquía mallorquina.

54 Las negociaciones se llevaron a cabo en enero de 1319 en el Palacio de Perpiñán. Por parte mallorquina actuó el propio Sancho mientras que por parte de la Corona de Aragón se presentó Bernat des Fonollar como representante de Jaime II (gerenti vicis procuratoris in Catalonie pro intame Jacobo generali procuratora) con una única mistón: hacer que Sancho I reconociera a Jaime II de Aragón como su heredero. Este deseo por parte de Jaime ll marcó la relación de ambos monarcas hasta la muerte de Sancho I en 1321. Santamarla, A.: Tensión Corona de Aragón - Corona de Mallorca...

5 El Collegi de la Mercaderia funcionaba en Mallorca desde mediados del sigio XIV - aunque no se reglamente oficialmente hasta 1409 con Martín el Humano-y el denominado Art de la Mercadería era la base económica en la que se sustentaban las tierras de Mallorca tal y como quedó reflejado años más tarde en la Lonja mallorquina. El ángel del pórtico de la Lonja lleva inscrito en el filacterio la divisa del colegio de mercaderes: Defenedors de la mercadería. 


\section{DOCUMENTACIÓN}

1319, noviembre, 6. Perpiñán.

Sancho I de Mallorca dona a los jurados y a la Universidad de Mallorca unos terrenos situados sobre un antiguo cementerio judío para su utilización como atarazana y otros usos públicos.

A. Signatura: Sancho 7. Orig. Perg. $330 \times 268 \mathrm{~mm}$. Gótica cursiva. Buen estado de conservación. Dorso: «n 53 / Carta dela donació del Cimiterium qui fo dels / judeus deuanta Santa Caterina / .signo. / Registram / Rey en Sanxo / octauo jorn novembris any M / CCC XVIIII. / 6 Nov... 1319 / D.R. / Donación del terreno / en donde estaba el Cimen / terio de Judíos a / la Universidad de / Mallorca.

Ed.: VICH, J., y MUNTANER, J.: Documenta Regni Maioricarum, Palma de Mallorca, 1945, Documento 114.

Noverint universsi quod Nos, Sancius, Dei gratia Rex Maioricarum, Comes Rossilionis et Ceritanie et dominus Montispesulani. Comoda subditorum nostrorum et illa potissima / que comunem utilitatem respiciunt ampliari et augeri volentes et singnantes et specialiter ea que ad comoditates et honores civitati Maioricharum / ad quam perrogatiua amore et beniuolencie afficimar gratis et ex dicta sciencia ac nostra liberalitate per nos et ommes nostros. Damus fidelibus / nostris iuratis et uniuerssitati ciuitatis predicte perpetuo illud solum seu terre spacium nostrum in quo fuit olim cimiterium iudeorum quod est / extra dicte civitatis portale quod dicitar de Portopinu. Quam donacionem de dicto solo seu spacio terre iuratis et uniuerssitati dicte / ciuitatis et eidem ciuitati facimus pure et libere tali condicione quod sit semper locus publicus et ad publicum et comune seruicium / depuiatus, videlicet per construantar ibi naues et alia vasa maritima. Et fiant ibidem cetera apta decensia et necessaria ac / utilia, prout requirit condicio ipsius loci et cuiuslibet alterius ad usum et seruicium publicum deputati prout iurati Maioricarum duxeret / ordinandum. Et sub hac condicionem dictam donacionem facimus et facere volumus et intendimus integriter ac generaliter siat melius, plenius / et utilius dici, scribi et intelligi potest ad comodum et utilitatem publicam ciuitatis predicte. In cuius rey testimonium et fidem presenti / carte nostrum iussimus appendi sigillum. Quod est actum Perpiniani octauo idus nouembris anno domini millesimo trecentesimo nonodecimo. / Ego Laurencius Plasensa scriptor prefaci domini nostri Regis ipsius mandato hanc cartam scribi feci et clausi meo publico sig (signum) no. 


\section{Traducción}

Sepan todos que Nos, Sancho, por la gracia de Dios Rey de Mallorca y conde de Rosellón y la Cerdaña y señor de Montpelier. Queremos abrazar y acrecentar los provechos de nuestros súbditos y que ellos mayormente guarden común utilidad y singularmente y especialmente a aquellos que tienen provecho y honores de la ciudad de Mallorca, los cuales tienen por adelantado amor y benevolencia de gusto y de cierta ciencia y de nuestra libertad para nosotros y para todos los nuestros. Damos a nuestros fieles jurados y a la universidad de la antes dicha ciudad uso permanente de aquel suelo o espacio de tierra nuestro que fue en otro tiempo cementerio de los judíos el cual está situado al exterior de dicho portal de la ciudad que se dice de Portopí. Hacemos donación de dicho suelo o espacio de tierra a los jurados y la universidad de la dicha ciudad y a sus ciudadanos hacemos sin reservas y franco de condiciones de tal modo que sea siempre lugar público y usado para público y común servicio, es decir para que allí construyan naves y otros equipos marítimos. Y que hagan aquí todas las otras cosas comunes y necesarias y útiles así como requiere la condición del dicho lugar y de todo lo otro para el uso y servicio público dispuesto así como lo ordenarán los jurados de Mallorca. $Y$ bajo esta condición hacemos dicha donación y queremos hacer y entendemos entero y general, más enteramente y más provechosamente decir y escribir y entender para la comodidad y utilidad pública de la ciudad antes dicha. En testimonio de la cual cosa y verdad presento nuestra carta a la que ponemos sello pendente. Hecha en Perpiñán el octavo idus de noviembre del año del señor de mil trescientos diecinueve.

Yo Lorenzo Plasencia, escribano de nuestro señor el Rey, por su mandato, hice escribir esta carta y puse mi sig (signo) no público.

Este mismo texto aparece en uno de los mejores libros conservados en el Archivo del Reino de Mallorca y que bajo el título de Llibre de Franqueses i Privilegis recoge las normas que decretaron los distintos monarcas mallorquines para el buen funcionamiento de su reino. La transcripción de los textos al libro se realizó en doble forma pues en la primera parte se trascriben de forma literal los documentos originales, mientras que en la segunda parte estos mismos documentos aparecen en lengua romance -catalán-. Cada uno de estos documentos consta de una pequeña regesta y la transcripción del documento.

Como complemento a este pequeño estudio adjunto la transcripción en lengua catalana del texto:

(signo) Carta de donació quel senyor rey afeta del ciminteri dels judeus quies fora laporta del portal de Portopí als iurats he ala Uniuersitat dela ciutat de Malorques en pertots temps que sia loch publich e comu ha seruey 
que aqui se fassen e altres uarels de mar e coses comunes axi con los iurats de Malorques hordonaran.

Sapien tuyt que nos en Sanxo, per la gracia de Deu rey de Malorques, comte de Rosselo e de Cerdanya e senyor de Muntpestler. Volens abrassar he crexer profits de nostres sotsmeses e que els maiorment que esguarden comuna utilitat e singularment e especial aquels qui a profits he ahonors son dela ciutat de Malorches, alaqual son tenguts per auansada amor e benuolensa de grat. E de certa sciencia e de nostra libertat per nos e per tots los nostres donam als feels nostres lurats e ala uniuersitat dela dita ciutat damunt dita en pertots temps aquel sol ho espay de terra nostra en que fosa enrere cementiri dels iudeus, la qual es fora lo portal dela ciutat que es dit de Portupi. La qual donació del dit sol ho espay de terra als iurats e ala uniuersitat dela dita ciutat e ha aquela ciutat fem purament e liberal en aytal condició que sia en per tots temps loch publich e apublic comu hus e seruey deputat. So es asaber que aqui se fassen e altres uexels de mar e ques fassen aqui totes altres coses comunes he necessaries he utils axi com requer la condició del dito loch e de tot altre a hus e ha seruey publich deputat axi con los iurats de Malorques a hordonarán. E sots aquesta condició la dita donació fem he fer uolem he entenem entegrament e general axi con nuls e pus plenerament e pus profitosa dir e escriure e entendre se pot ha profit e utilitat publica dela ciutat damunt dita. En testimoni dela qual cosa e afe aquesta present carta ab nostre segel pendent fem segelar. Fet es assó a Perpenyá VIII idus nouembre. Anno domini millesimo CCC $^{\circ}$ XIX․ 10 Lorens Plasensa escriuá del damunt dit senyor nostre rey de manament del aquesta carta fiu escriure e cloy ablo meu publich sen (signo) yal.

\section{BIBLIOGRAFÍA}

bafceló Crespi, María: «Retrat de la Ciutat de Mallorca cinc-cents anys enrere (aspectes urbanistics)", Estudis Baleàrics, n. 41 , Palma de Mallorca, octubre, 1991.

BeINART Haim: Los judfos en España, MAPFRE, S.A., Madrid, 1992.

CANTERA MONTENEGRo, Entique: Aspectos de la vida cotidiana de los judíos en la España modieval, UNED, serie "Aula Abierta», Madrid, 1998.

Cateura Bennasser, P.: Las instalaciones portuarias de la Ciudad de Mallorca (1300-1350). XIII Congreso de Historia de la Corona de Aragón.

- "Mallorca a la segona meitat del segle XIII (Aspectes polítics i financers fins a 1276)», Estudis Baleàrics, 17, Palma de Mallorca, 1985.

- «Repoblación, urbanización y comercio. El puerto de la Ciudad de Mallorca durante el siglo Xili", Mayurca, n. ${ }^{\circ} 21$, Paima de Mallorca, 1987.

Dufouro, Charles-Emmanuel: L'Espagne catalane et le Maghrib aux Xur et xive siecles, Presses Universitaires de France. 1966.

Durliart, Marcel: L'art en el Regne de Mallorca, Editorial Moll, Palma de Mallorca, 1989.

Ferran Soldevila: Les quatre grans cròniques, Editorial Selecta, Barcelona, 1971. 

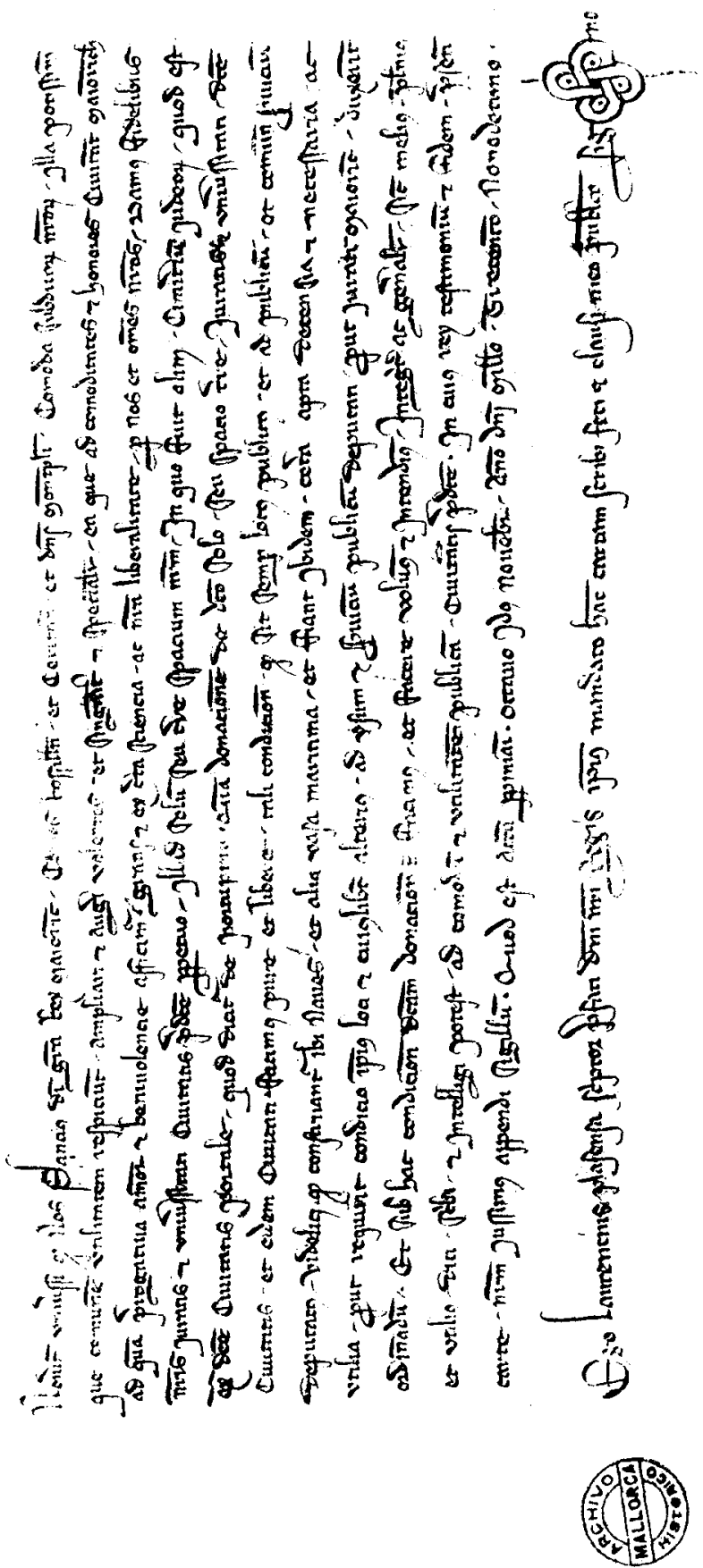
FITA, Fidel, y Llabrés, Gabriel: “Privilegios de los Hebreos mallorquines”, Boletín de la Real Academia de la Historia, tomo XXXVI, Madrid, 1900.

Huici Miranda, A., y Cabanes Pecourt, M.D.: "Documentos de Jaime I de Aragón. Vol. V (1263-1268)", Textos Medievales, 77, Zaragoza, 1988.

Liber Maiolichinus de gestis pisanorum illustribus, traducción al catalán por MULET MAS, Mireia, Palma de Mallorca, 1991.

MaRTinez FerRando, J. Ernest: La tràgica història dels Reis de Mallorca, Editorial AEDOS, Barcelona, 1960.

Peña Nicolau, Pedro de Alcántara: Antiguos recintos fortificados de la Ciudad de Palma, Editorial mallorquina de Francisco Pons, Palma, 1956.

Pérez Herrero, Enrique: “Apuntes para el estudio de las necrópolis judías de época medieval o ensayo de tipología sepulcral», SEFARAD, n. XXXVIII, Madrid, 1978.

PIÑA Homs, Román: La creación del Derecho en el Reino de Mallorca, Ediciones Cort, Palma de Mallorca, 1987.

Pons, Antonio: Los judios del Reino de Mallorca durante los siglos XIII y XIV, 2 vols., Miguel Font, Editor, Palma de Mallorca, 1984.

Riera Frau, M." Magdalena: Evolució urbana i topografia de Madîna Mayûrca, Ayuntament de Palma, Palma de Mallorca, 1993.

Romano, David: “Aljama frente a judería, call o sus sinónimos", SEFARAD, $n .{ }^{\circ} \mathrm{XXX} X \mathrm{X}, \mathrm{Ma}-$ drid, 1979.

Santamaría, Álvaro: Ejecutoria del Reino de Mallorca, Ajuntament de Palma, 1990.

- "La política municipaı de Alfonso el Liberal en el Reino de Mallorca (1285-1291). La ciudad hispánica durante los siglos XIII al XVI", Actas del coloquio celebrado en La Rábida y Sevilla del 14 al 19 de septiembre de 1981, Universidad Complutense, Madrid, 1985.

- Tensión Corona de Aragón - Corona de Mallorca. La sucesión de Sancho de Mallorca (1318-1326), en La España Medieval, III, Estudios en memoria del profesor D. Salvador de Moxó, Universidad Complutense, Madrid, 1982.

SASTRE Moll, Jaime: "El puerto de la Ciutat de Mallorca durante el reinado de Sancho la regencia de Felipe de Mallorca (1311-1330). Rentas reales portuarias y su reinversión", Miscel.lània de textos medievals, n. ${ }^{\circ} 7$, C.S.I.C., Institució Milà i Fontanals, Departament d'Estudis Medievals, Barcelona, 1994.

SEvilzano Colom, Francisco: "De la Cancilleria de los Reyes de Mallorca (1276-1343)", Instituto Nacional de Estudios Jurídicos, Anuario de Historia del Derecho Español, Madrid, 1972.

- Mercaderes y navegantes mallorquines (siglos XII-XV), en Historia de Mallorca, dirigida por Mascaró Pasarius, tomo IV, Palma de Maliorca, 1974.

- Movimiento portuario de Mallorca. Relaciones marítimas del puerto de Mallorca, en Historia del puerto de Mallorca, Diputación de Palma de Mallorca, 1974.

TEDESCHI, Mario: Polémica y convivencia de las tres religiones, MAPFRE, S.A., Madrid, 1992. VILLANUEVA, Jaime: Viaje literario a las Iglesias de España, Madrid, 1852, tomo XXII. 